\title{
El poder del discurso del Gobierno de Corrientes en la prensa durante el periodo preelectoral $2013^{*}$
}

\author{
Mariana Noemí Blanco**
}

\section{Resumen}

Este artículo brinda algunas conclusiones preliminares de una investigación en curso sobre los efectos del discurso del Gobierno de la Provincia de Corrientes en la prensa. El análisis interdiscursivo incluye gacetillas despachadas por la Dirección de Información Pública (DIP), órgano oficial de difusión de los actos de gobierno, y las tapas y noticias de primera plana publicadas por los diarios El Litoral, Época y Norte de Corrientes durante el periodo preelectoral 2013. Para este trabajo se abordó la categoría poder del discurso desarrollada por Eliseo Verón. También se propone articular herramientas teórico metodológicas de autores de tradición sociosemiótica como Patrick Charaudeau y Lucrecia Escudero, con nociones de los estudios de rutinas periodísticas de diarios en contexto de periferia.

\section{Palabras clave}

Poder del discurso - gramáticas de reconocimiento - prensa y gobierno.

\footnotetext{
* Artículo recibido el 20 de Abril de 2016. Aceptado el 17 de Julio de 2016.

** Licenciada en Comunicación Social - Universidad nacional del Nordeste - Argentina. Correo electrónico: maryamblanco@gmail.com
} 


\title{
The Corrientes Government Discourse's power on the press during the pre-election period 2013.
}

\begin{abstract}
This article provides some preliminary conclusions of an ongoing investigation on the discourse's effects of the Government of the Province of Corrientes in the discourse of provincial dailies. The interdiscursive analysis included press releases released by the Department of Public Information, and tops and headline news published by the dailies El Litoral, Época and Norte de Corrientes during the pre-election period 2013.This paper addresses the category power of discourse developed by Eliseo Verón. It is also proposed to combine theoretical methodological tools of semiotician authors as Patrick Charaudeau and Lucrecia Escudero, with notions of journalistic routines studies in context periphery.
\end{abstract}

\section{Keywords}

Discourse's power - grammar of the recognition - press and goverment.

\section{Introducción}

El poder de un discurso se puede observar en otro discurso que es su efecto. Al tomar esta categoría desarrollada por el semiólogo argentino Eliseo Verón (1980, 1988, 1993 y 2004), la propuesta de este artículo consiste en brindar algunas conclusiones preliminares de una investigación en curso sobre los efectos de reconocimiento de las gacetillas de prensa despachadas por la Dirección de Información Pública (DIP) del Gobierno de la Provincia de Corrientes en las noticias de los diarios El Litoral, Época y Norte de Corrientes durante el periodo preelectoral $2013^{1}$. Si bien las bases teóricas de este trabajo se sustentan en la perspectiva veroniana, se pretende ampliar el enfoque del autor con la incorporación de herramientas teórico-metodológicas de tradición sociosemiótica desarrolladas por Patrick Charaudeau (2003 y 2009) y por Lucrecia Escudero (1996) para el análisis de los efectos de reconocimiento.

Además, en esta investigación se articulan nociones de los estudios de rutinas periodísticas de diarios en contexto de periferia (Arrueta, 2010), entendiendo que los

\footnotetext{
${ }^{1}$ Este artículo brinda algunos avances de una investigación en etapa de conclusiones que lleva por nombre El Poder del Discurso del Gobierno de la Provincia de Corrientes en los medios gráficos durante el periodo preelectoral 2013, en el marco de un trabajo de tesina de la carrera de Licenciatura en Comunicación Social de la Facultad de Humanidades de la Universidad Nacional del Nordeste.
} 
elementos constitutivos del contexto institucional de un medio de comunicación -sean políticas profesionales, línea editorial, valores noticias, políticas sobre el uso de fuentes de información, entre ellas, las gacetillas de prensa- integran las condiciones de reconocimiento de la prensa.

En su teoría de los discursos sociales, Verón (1988, 1993 y 2004) propone tres planos analíticos para acceder a un fragmento de la red semiótica: la producción, que se interesa por lo ideológico; el reconocimiento, que aborda el problema del poder de un discurso, entendido como efecto; y la circulación, que es el desfase entre ambos planos.Este estudio se posiciona en el polo del reconocimiento, por lo que intenta reconstruir las gramáticas de reconocimiento de la prensa en relación con el discurso gubernamental. Aquí se entiende por gramáticas de reconocimiento a un conjunto de reglas que describe operaciones que dejan huellas en la superficie discursiva (Verón, 1993 y 2004).

La red semiótica, al ser infinita,requiere de la delimitación de lo que en este artículo llamaremos discurso gubernamental. En este trabajo, por lo tanto, tomamos únicamente las gacetillas de prensa despachadas por la DIP, órgano que centraliza la información de otros departamentos ministeriales de prensa para difundir a los medios de comunicación y que también publicita los actos de gobierno a través de envíos de cobertura propia. El análisis interdiscursivo se realizará con las noticias publicadas en tres diarios de circulación provincial, El Litoral, Época y Norte de Corrientes, en el periodo comprendidodel 1 al 8 de marzo, del 13 al 20 de junio y del 1 al 8 de septiembre de 2013.

Este trabajo abordará el periodo preelectoral 2013 para identificar variaciones en el discurso gubernamental en la prensa a medida que se aproximan las elecciones. Ese año, los electores de Corrientes concurrieron a los centros de votación en tres ocasiones para elegir cargos ejecutivos y legislativos. Estas fechas incluyeron las PASO (Primarias Abiertas, Simultáneas y Obligatorias), generales legislativas nacionales y la gobernación. Esta última elección se concretó el 15 de septiembre de 2013 cuando también se votaron intendentes y concejales en los municipios. Las fórmulas con mayor intención de votos fueron Encuentro por Corrientes (ECO) y el Frente para la Victoria (FPV). Ricardo Colombi (ECO) buscaba ser el primer gobernador de la provincia en ser reelecto, mientras que el otrora intendente de Corrientes Capital, Carlos Mauricio "Camau" Espínola (FPV), intentaba lograr el máximo cargo del Ejecutivo provincial con apoyo del Gobierno nacional de Cristina Fernández de Kirchner.

Si bien la campaña oficial está estipulada en el calendario electoral luego del cierre de listas de los candidatos, otro de los criterios por el cual se efectuó un corte de mayor amplitud se debió a que la campaña puede extenderse inclusive durante la gestión gubernamental por la presencia de distintos actores políticos y la mayor exposición de 
éstos y del Gobierno en los medios de comunicación ${ }^{2}$, fenómeno que ha sido definido por los teóricos de la comunicación política como campaña permanente (Izurieta, Perina y Arterton, 2002).

Diversos autores estudiaron el discurso político tanto desde su dimensión gubernamental y de campaña como desde su relación con los medios de comunicación (Charaudeau, 2009; Elizalde, Fernández Pedemonte y Riorda, 2006 y 2011; Escudero et. al, 2002; Escudero y García Rubio, 2007; Izurieta, Perina y Arterton, 2002; Rincón, 2004; Sartori, 1998). Sin embargo, escasos son los trabajos en Corrientes específicos en el área ${ }^{3}$.

Conocer los efectos del discurso gubernamental en la prensa, por lo tanto, permite observarlos comunicados oficiales como herramienta de comunicación política para intentar instalar agenda en medios gráficos. Además, pretende dar cuenta de las tensiones entre ambas instancias discursivas para legitimar la palabra en periodo preelectoral.

\section{Propuesta teórico-metodológica}

Como hemos mencionado en la introducción, la propuesta teórico-metodológica de este trabajo pretende ampliar la perspectiva veroniana con el uso de herramientas de tradición sociosemiótica, tanto para el análisis del discurso de la información (noticias) como del político institucional (gacetillas). También se han incorporado nociones de los estudios de rutinas periodísticas de los diarios en contexto de periferia.

Para este trabajo el relevamiento se dividió en dos etapas. Un barrido preliminar que incluyó 299 gacetillas de prensa de la DIP y 72 ejemplares de diarios que fueron publicados durante los tres cortes establecidos. Una vez identificados contenidos y temáticas coincidentes entre los comunicados y las noticias, se optó por seleccionar 25 noticias de portada -y sus correspondientes tapas- y 18 partes oficiales.

Por lo tanto, el corpus está integrado por diez noticias publicadas en marzo de 2013, cinco en El Litoral, dos en Época y tres en Norte de Corrientes; estas se compararon con seis comunicados de la DIP. En junio de ese año fueron cuatro noticias, de las cuales una se publicó en El Litoral, otra en Norte de Corrientes y dos en Época; en contraste con dos gacetillas. En septiembre de 2013 se abordaron once noticias, cuatro publicadas en El Litoral, seis en Época y una en Norte de Corrientes; y diez partes oficiales.

\footnotetext{
${ }^{2}$ El Código Electoral de Corrientes no establece un periodo de campaña ni una definición de esta como sí lo estipula la Ley Nacional. No obstante, se considera que la campaña inicia formalmente con el cierre de listas de candidatos que en esa ocasión, para el caso de la Gobernación, fue el 27 de julio de 2013. Por ello, en este trabajo se utiliza el término periodo preelectoral.

${ }^{3}$ Tras la revisión bibliográfica para esta investigación se han identificado escasos trabajos desde el enfoque veroniano sobre la relación de la prensa con el Gobierno de Corrientes. Entre ellos, se puede mencionar una tesis de grado de la carrera de Comunicación Social de la UNNE sobre estrategias de comunicación del Gobierno de la Provincia de Corrientes (Apezteguía Avellán, 2007).
} 
Como el objetivo de este estudio es identificar efectos de reconocimiento, se deben describir gramáticas de reconocimiento. Para ello, la noción de operación es fundamental. Una operación refiere a la relación entre el discurso y sus condiciones históricas y sociales de reconocimiento. Verón (1993) se aleja de un análisis inmanente del discurso, puesto que las condiciones sociales dejan marcas en la superficie discursiva. Una vez establecidas las relaciones entre estas marcas y las condiciones sociales del discurso, es posible detectar huellas que son un índice de las condiciones de reconocimiento.

El modelo básico de una operación está conformado por un operador, que es una marca en la superficie. También por un operando, aquello a lo que se remite; y por la relación que los une (Bitonte, 2009). Por ejemplo, las comillas (operador) es una marca de una cita textual en una noticia que remite a la palabra de un actor (operando), al discurso de un actor. La relación entre ambos es una operación intertextual.

Para este trabajo se observaron operaciones referenciales (Verón, 2004; Bitonte, 2009) que pueden ser de designación -cómo son nombrados personajes y sucesos en las gacetillas y luego en la prensa-. Esto permite identificar los principales actores que son puestos en el relato noticioso, así como las imágenes de adhesiones al discurso político que pueden ser de credibilidad y de identificación (Charaudeau, 2009), al mismo tiempo que permite detectar imágenes de destinatario y contradestinatario (Verón, 1987b). Aquí también pueden ponerse en relación las representaciones que construye el gobierno a través de los partes oficiales y las representaciones en los medios de comunicación.

Otro tipo de operaciones son las de encuadre, aludiendo a un encuadre semántico o semantización del acontecimiento (Verón, 2004 y 1971). En este plano se puede observar lo que Verón denominó la construcción de la temporalidad social, la cual puede ser atomizada -cuando el acontecimiento en tapa no se relaciona semánticamente con otros-; o por el contrario, puede ser de articulación con otros acontecimientos.

Salvando las distancias epistemológicas, la idea de construcción de la temporalidad social puede emparentarse con la noción de agenda mediática, desarrollada por la sociología norteamericana (McCombs, 2006). Su articulación con la sociosemiótica fue propuesta por Escudero (2007) para el análisis de la prensa en contexto de campaña electoral.

A esta caja de herramientas podemos incorporar las operaciones intertextuales, fundamentales para detectar las huellas del discurso gubernamental en las noticias. Verón (2004) hace referencia a la alusión como una operación intertextual ya que no solo interpela al conocimiento del lector, sino que, a su vez, remite a otros textos. Para este trabajo, además, se agregaron elementos indicadores de relaciones de intertextualidad como las fuentes de información (Escudero, 1996; Charaudeau, 2003) y el dicho referido, el cual, según explica Charaudeau (2003), genera tres tipos de 
operaciones: selección -permite detectar qué fragmentos de las gacetillas de prensa se seleccionaron para construir la noticia-; identificación de los elementos -si se nombran o no a los actores que son los productores del discurso original-; manera de referir el discurso original -cita textual en estilo directo, cita textual en estilo indirecto, integrado al discurso o narrativizado o alusión-.

Al mismo tiempo, para aproximarnos a las condiciones de reconocimiento de la prensa, se tomaron nociones de los estudios de rutinas periodísticas en contexto de periferia (Arrueta, 2010) que incluyeron el origen político de los medios analizados, la composición de la redacción, políticas profesionales, división del trabajo y línea editorial ${ }^{4}$. Para ello, se articularon técnicas de revisión bibliográfica y entrevistas semiestructuradas a periodistas.

Por razones metodológicas, aquí nos posicionamos en las condiciones de reconocimiento de la prensa. Sin embargo, a futuro, ello no clausura el análisis de las condiciones de producción de la prensa, ya que "toda gramática de producción puede examinarse como resultado de determinadas condiciones de reconocimiento; y toda gramática de reconocimiento solo puede verificarse bajo la forma de un determinado proceso de producción" (Verón, 1993:130).

\section{Condiciones de reconocimiento de la prensa}

El contexto político-histórico, el económico y social, y el contexto institucional de los medios de comunicación pueden observarse como condiciones de reconocimiento de la prensa. Dado que para Verón (1993 y 2004) la dimensión discursiva construye la realidad social, en este trabajo los contextos mencionados pueden considerarse como "elementos extradiscursivos" en el sentido de que no integran el corpus seleccionado.

Teniendo en cuenta esta aclaración, es posible marcar algunos elementos extradiscursivos que se detectaron para este estudio como restricciones de reconocimiento de la prensa. Algunos de ellos son la población y distribución geográfica de la provincia de Corrientes (Indec, 2013b), centralizada en Corrientes Capital, que contribuye a una mayor visibilidad de los acontecimientos provenientes de la Capital provincial. Otra de las restricciones de reconocimiento es la estructura económica, modelo que se sustenta en el sector primario de la provincia de Corrientes (DEyCa yDEyCb, 2013), jurisdicción que se ubica entre las que poseen los indicadores

\footnotetext{
${ }^{4}$ La línea editorial es entendida como "un conjunto de coordenadas espacio-temporales e ideológicasprofesionales desde donde se intenta dar sentido a los mecanismos periodísticos de inclusión, exclusión, jerarquización y tematización" (Arrueta, 2010:126). Para entender estas coordenadas se deben identificar valores editoriales invisibles, entre las cuales se pueden mencionar la posibilidad de lucro, el medio como actor político, el medio como actor vecinalista o social (Arrueta, 2010). Esto es, diferenciar entre el horizonte instituido del medio, es decir lo que manifiesta como línea, ya sea a través de un eslogan, editoriales o manual de estilo; y el horizonte instituyente, es decir lo que se puede vislumbrar, ya sea desde las negociaciones internas de las redacciones o de la selección y tratamiento de los contenidos.
} 
de pobreza más altos del país (Indec, 2013a). Esto impacta en el financiamiento de las empresas periodísticas, las cuales, en su mayoría, dependen de la pauta publicitaria estatal $\left.\right|^{5}$.

Además, entre las condiciones de reconocimiento se pueden mencionar el origen y el vínculo político de los medios de comunicación de Corrientes Capital; una política provincial de alianzas partidarias en modificación y en consonancia con los clivajes de la política partidaria nacional ${ }^{6}$. Uno de los principales elementos que configura las restricciones de reconocimiento son las elecciones 2013 para gobernador y vicegobernador, con la polarización en la intención de votos entre el frente gobernante, Encuentro por Corrientes (ECO), y el Frente para la Victoria (FPV), este último con apoyo del Gobierno nacional de Cristina Fernández de Kirchner.

En cuanto al contexto institucional ${ }^{7}$, es posible mencionar algunos elementos a los fines de describir los medios de comunicación seleccionados. Los tres diarios tienen su origen como actor político. En el caso de Norte de Corrientes, comenzó a publicarse en 2012 como una expansión empresarial de Editorial Chaco SA, que edita el diario Norte, de propiedad de Raúl Rolando "Tato" Romero Feris, gobernador de Corrientes entre 1993-1997 y líder político del Partido Nuevo (PaNu). Su línea editorial es considerada por los entrevistados como crítica al gobierno provincial. De acuerdo con información proporcionada por los entrevistados, es posible inferir dos valores editoriales invisibles predominantes, el medio como actor político y como actor social.

Fundado en 1963 por el empresario ganadero Juan Romero, padre de "Tato" y de Carlos Romero Feris-actual director del diario-, El Litoral estuvo ligado en un principio al Partido Autonomista. Cumple con un principio de despersonalización al no poseer una línea definida sino sujeta a condicionamientos políticos, económicos y sociales. Ese año se consideraba oficialista ya que recibía pauta del Gobierno de la Provincia de Corrientes.

En su horizonte instituido, el medio se define como tribuna de voces ya que brindaría espacio a la palabra de distintos sectores. En su horizonte instituyente es posible inferir dos valores editoriales invisibles predominantes: la posibilidad de lucro y el medio como actor social y político.

En 1973 salió a la plaza local el diario Época, de propiedad de Julio Romero, gobernador peronista entre 1973-1976.Su línea es considerada popular y conservadora. En ese entonces, oficialista por recibir pauta del Estado provincial. En su horizonte instituido, con el eslogan "La verdad a diario", apunta a un principio de

\footnotetext{
${ }^{5}$ Para un mayor análisis del mapa de medios y su estructura económica ver De los Reyes (2012).

${ }^{6}$ Para una ampliación de estudios sobre política partidaria, cultura política y protesta social en Corrientes ver Artese (2005), Barrios (2005), Behrend (2003), Guber (2002), Solís Carnicer(2006), Villarino y Stembeng (2005).

${ }^{7}$ Los datos se corresponden a entrevistas realizadas en 2013 a cinco periodistas de los diarios El Litoral, Época y Norte de Corrientes; y a consulta bibliográfica.
} 
"descubrimiento de lo oculto". En su horizonte instituyente, en tanto, es posible inferir dos valores editoriales invisibles predominantes, la posibilidad de lucro y el medio como actor social y político.

Con una tirada de más de 18 mil ejemplares los domingos, certificada por el IVC, Época es el diario provincial de mayor circulación. El Litoral y Norte de Corrientes intentan expandir su mercado con la incorporación de publicaciones y productos complementarios como revistas, suplementos, páginas web y redes sociales.

Época, por su parte, es el diario con mayor espacio destinado a publicidad del sector privado. Al momento de realizarse este estudio, contaba con pauta oficial del Estado provincial, nacional y de la Municipalidad de Corrientes. Con la ampliación del tiraje, El Litoral intentaba acomodarse en el mercado publicitario privado y también contaba con pauta oficial de estas tres órbitas estatales mencionadas. Norte de Corrientes presentaba una proporción inferior de publicidad privada, la mayoría del diario Norte editado en el Chaco, y no cuenta -a la fecha- con pauta estatal. Desde los tres diarios, los entrevistados para esta investigación consideraron que tanto la ausencia como presencia de pauta repercute en la línea editorial.

En 2013, El Litoral contaba con 24 periodistas en su redacción, Época con 19 y Norte de Corrientes con 20 periodistas. En los tres medios se observó un proceso de recambio generacional, ya que las edades promedio rondaban entre los 30 y 40 años, evidenciándose una transición del llamado "periodista de oficio" al periodista con formación académica, debido a que entre el 70\% y 80\% tiene título universitario del nivel de Tecnicatura. No obstante, la mayoría no completó su formación de grado. Tampoco se registraba un sistema de capacitación continua en las empresas periodísticas.

En cuanto a las rutinas periodísticas y políticas profesionales, la cobertura propia y consulta a más de una fuente de información fueron las principales premisas expresadas por los entrevistados en las tres redacciones. Estas políticas se explicitan a los ingresantes, luego es tácita. Si bien los informantes manifestaron que existen instancias de autoevaluación, estas no están sistematizadas. Tampoco se registra un manual de estilo en los tres medios gráficos.

En relación con la organización del trabajo, en El Litoral el horario de ingreso no es fijo y generalmente casi la totalidad del diario edita por la tarde. No están condicionados por el horario de cierre a excepción de los sábados, día de mayor tirada, ya que se edita la publicación del domingo. Época y Norte de Corrientes mantienen dos turnos. En el caso del primero, la mayoría de la redacción trabaja por la tarde; en el segundo, por la mañana.

Los entrevistados coincidieron en que los comunicados oficiales forman parte de la rutina periodística de los tres diarios al ser una fuente de información de consulta diaria. Las gacetillas se remiten a una amplia nómina de periodistas a través de correos electrónicos. De acuerdo con un relevamiento para este estudio, los comunicados 
oficiales se utilizan para elaborar recuadros y noticias de cabezas de páginas en el cuerpo de los diarios.

Por otra parte, el público meta se evalúa de manera intuitiva y de acuerdo con la venta y por indicadores de acceso a través de las ediciones digitales. Los tres diarios, según la percepción de los entrevistados, apuntan a un público estándar de ingreso medio y de mediana edad, ya que consideran que los jóvenes se inclinan por el soporte digital.

Estos elementos mencionados operan de manera dinámica en la construcción del acontecimiento noticioso, restricciones que se entretejen en la red de significación del discurso de la información que contribuirán a detectar los efectos de reconocimiento del discurso gubernamental en los medios gráficos analizados.

\section{Efectos de reconocimiento}

El objetivo de este trabajo fue detectar reglas de lecturas de los comunicados por parte de la prensa. Estas gramáticas de reconocimiento se observaron a través de operaciones de asignación de sentido en los discursos. Ello, mediante la identificación de operaciones de encuadre, referenciales e intertextuales.

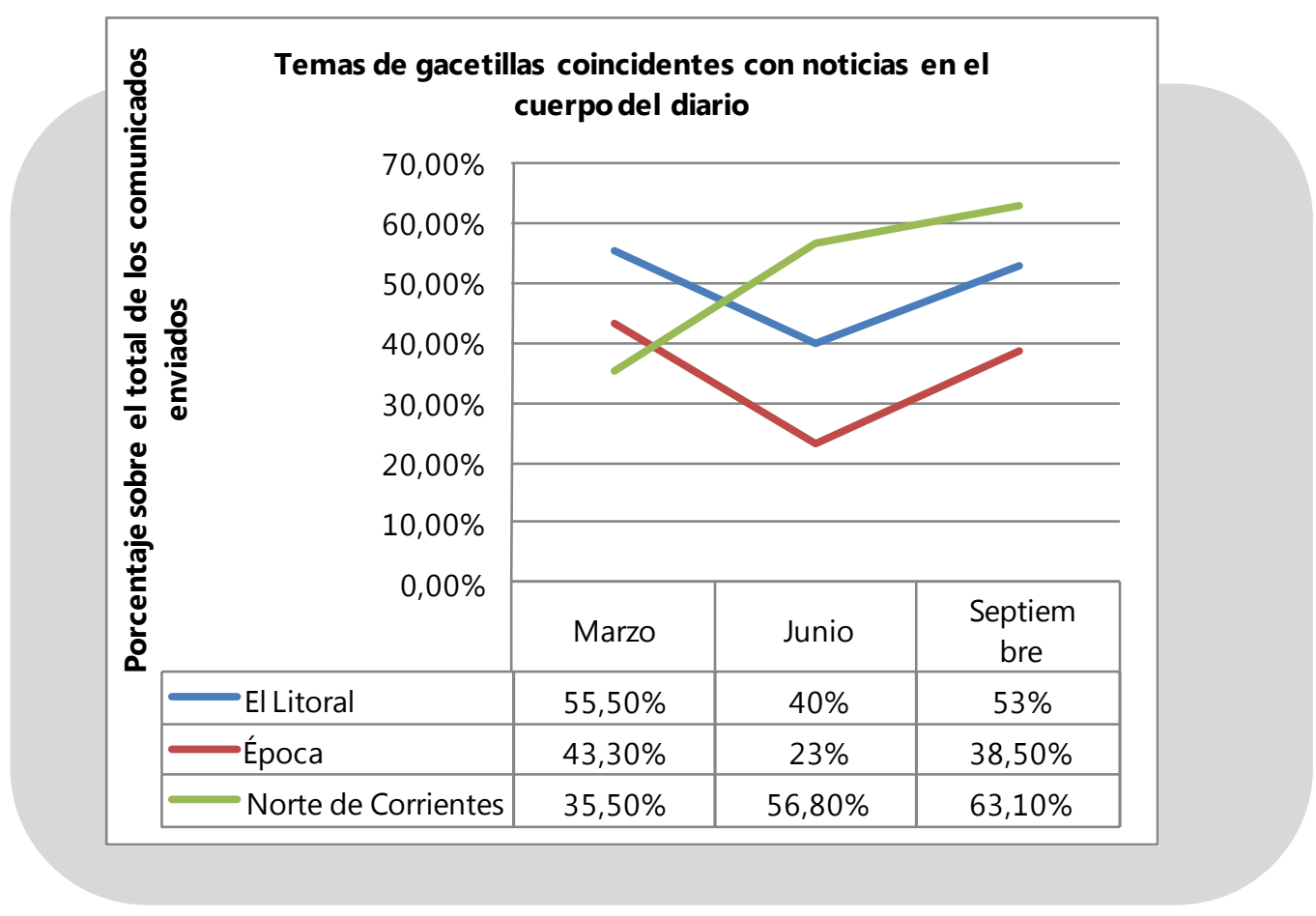

Sin embargo, antes de avanzar con la identificación de operaciones, primero observaremos la presencia de gacetillas en los medios seleccionados en términos cuantitativos, producto de un barrido preliminar de 299 gacetillas y 72 ejemplares de diarios durante el periodo seleccionado. A modo general es posible establecer que los comunicados oficiales tienen mayor espacio en el cuerpo de los diarios antes que en 
los espacios de mayor visibilidad como es el caso de las tapas. Además, se pudo establecer que los diarios no publicaron mayor cantidad de partes oficiales a medida que se aproximaba el año electoral. En las portadas, la tendencia es decreciente en Época y Norte de Corrientes, mientras que El Litoral registra un incremento en septiembre, pero que no es mayor a marzo.

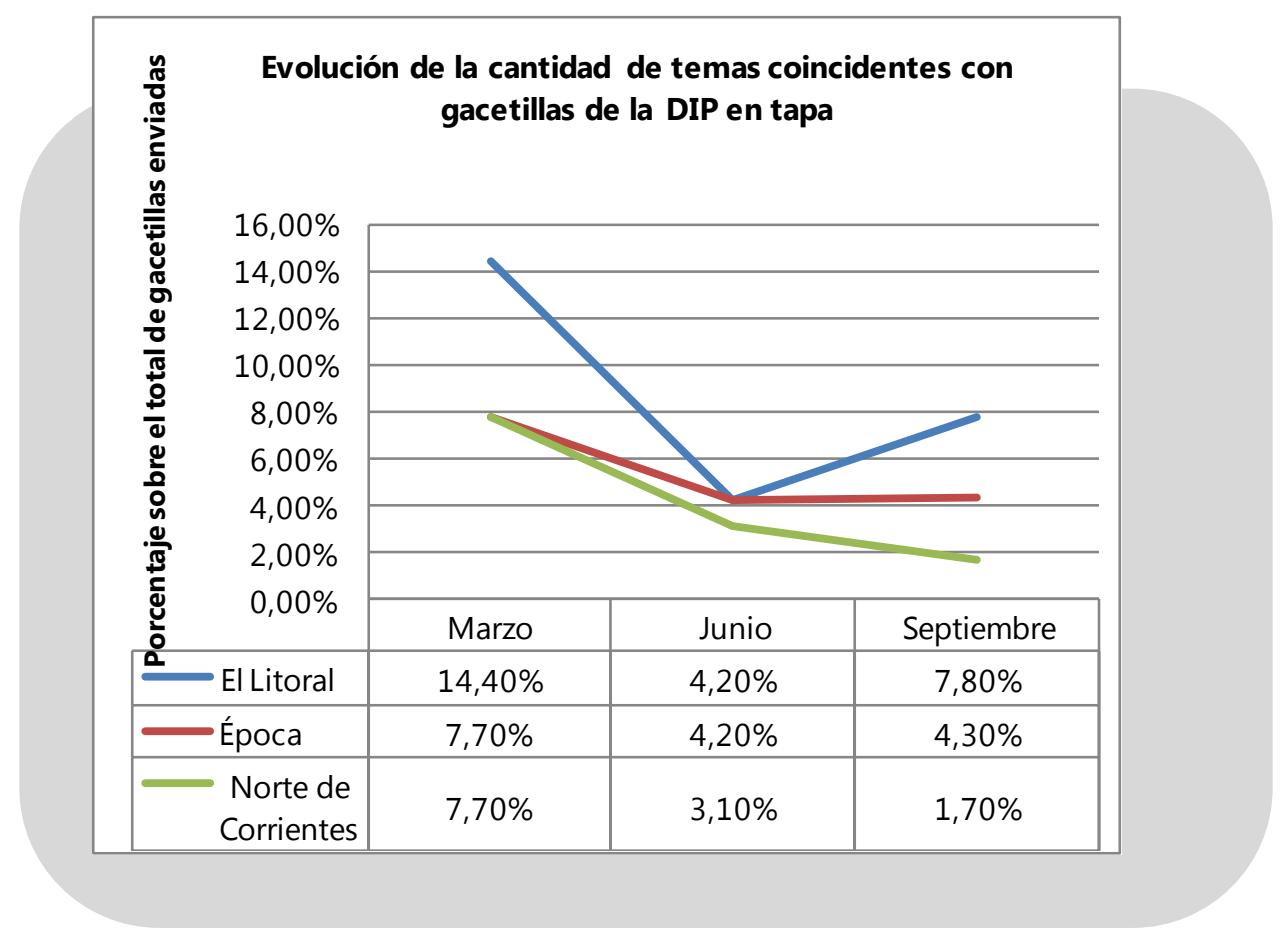

Este primer relevamiento, por lo tanto, permitió observar que los temas más cuantificados en la tapa de los diarios durante el periodo seleccionado fueron policiales, deportes y campaña electoral. Policiales y deportes fueron los temas con más presencia en las portadas en los cortes de marzo y junio.

En septiembre, la campaña electoral irrumpió en la agenda de los tres medios con más del $20 \%$ de las noticias publicadas en primera plana correspondientes al acto eleccionario. En este último corte, la temática electoral no solo fue la más cuantificada, sino también la de máxima jerarquización, por lo tanto de mayor visibilidad, advirtiéndose así las elecciones a gobernador como una condición fundamental de reconocimiento del discurso gubernamental en la prensa.

Ahora bien, para identificar los efectos de reconocimiento del discurso gubernamental en los diarios seleccionados se han tomado 25 noticias de máxima visibilidad, publicadas como título principal y como título de fotos principales de tapa, con el propósito de detectar reglas de lectura.

Una regla de reconocimiento identificada en el corpus se relaciona con el encuadre semántico en los títulos de las noticias. Las lecturas de las gacetillas por parte de la prensa no necesariamente deban ser lineales, independientemente de si el medio tenga 
o no pauta oficial, o si coincide o no con su línea editorial. El medio construye el acontecimiento teniendo en cuenta la agenda mediática, su propia construcción de la temporalidad social, las políticas profesionales que operan en la redacción, las especificidades del discurso de la información ${ }^{8}$, el contexto político -elecciones, conformación de alianzas-, una serie de elementos que contribuye, en la mayoría de los casos analizados, a no realizar reproducciones directas de los comunicados en los espacios de mayor visibilidad como titulares.

A continuación, por razones de espacio, observaremos algunos ejemplos sobre cómo opera el discurso gubernamental como condición de reconocimiento de la prensa en relación con otros elementos "extradiscursivos". En marzo irrumpió en la agenda mediática la campaña electoral. La apertura de la Asamblea Legislativa se construyó como parte de esta, pese a que la DIP trató el hecho como un acto institucional. En ningún extracto de los partes oficiales enviados hubo referencias explícitas a la campaña o a las elecciones, no así implícitamente se abordó en algunos fragmentos la construcción de un contradestinatario, un modelo nacional frente a un modelo local.

El 1 de marzo se enviaron cuatro gacetillas que trataron la Asamblea Legislativa, de las cuales tres coincidieron con contenidos jerarquizados en tapa en los diarios del 2 de marzo. "La solidez y confianza social nos permitieron sumar esfuerzos para encaminarnos a un futuro de progreso" (DIP, 1 de marzo de 2013); "Discurso completo del gobernador Ricardo Colombi" (DIP, 1 de marzo de 2013); "Ricardo Colombi emitió su mensaje anual ante la Legislatura con acompañamiento de diversos sectores de la sociedad" (DIP, 1 de marzo de 2013), son los títulos de los comunicados mencionados.

Las gacetillas construyeron el acontecimiento en torno al discurso del gobernador. Hicieron referencia a un acto institucional, la apertura de sesiones ordinarias, y no al proselitismo. Los medios, por su parte, explicitaron el tópico electoral, en relación con el acto institucional en sus ediciones del 2 de marzo de 2013: "Con un duro discurso de campaña, Colombi inauguró el periodo de sesiones ordinarias" (El Litoral, 2 de marzo de 2013); "Colombi diferenció su gestión de la política nacional con matriz del ' $90^{\prime \prime \prime}$ (Época, 2 de marzo de 2013); “Colombi se victimizó ante el gobierno nacional y criticó al kirchnerismo local" (Norte de Corrientes, 2 de marzo de 2013).

\footnotetext{
${ }^{8}$ Para una mayor descripción del discurso de la información ver Charaudeau (2003) y Escudero (1996). Fernández Constantinides (2011) expresa sus reparos sobre la utilización del término discurso de la información y opta por discurso periodístico.
} 


\section{EL LITORAL}

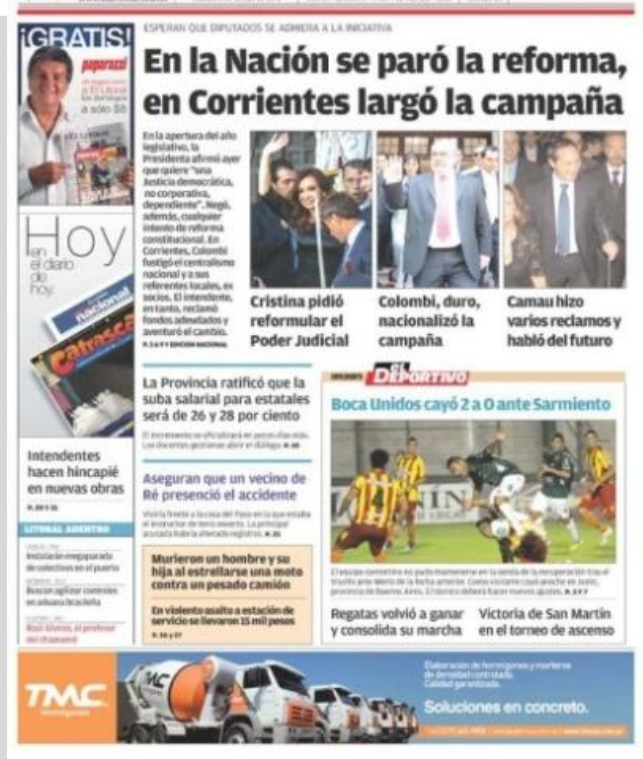

Tapa del diario Norte de Corrientes, 2 de marzo de 2013.

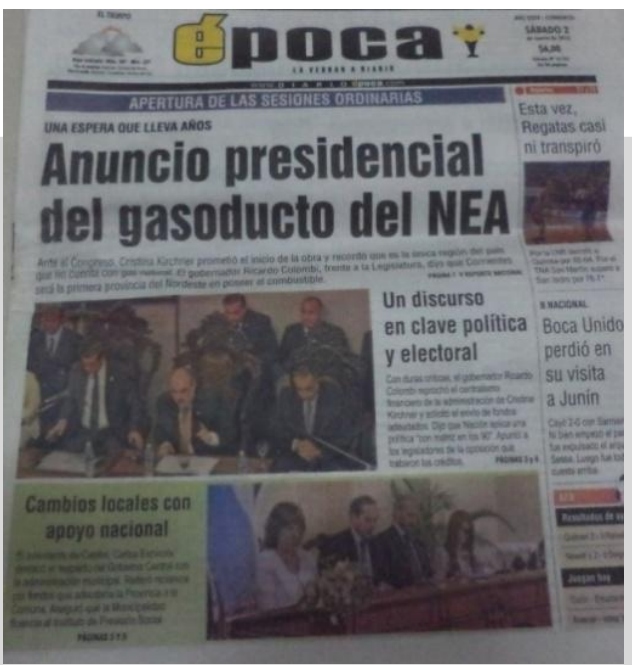

Tapa del diario Época, 2 de marzo de 2013. 


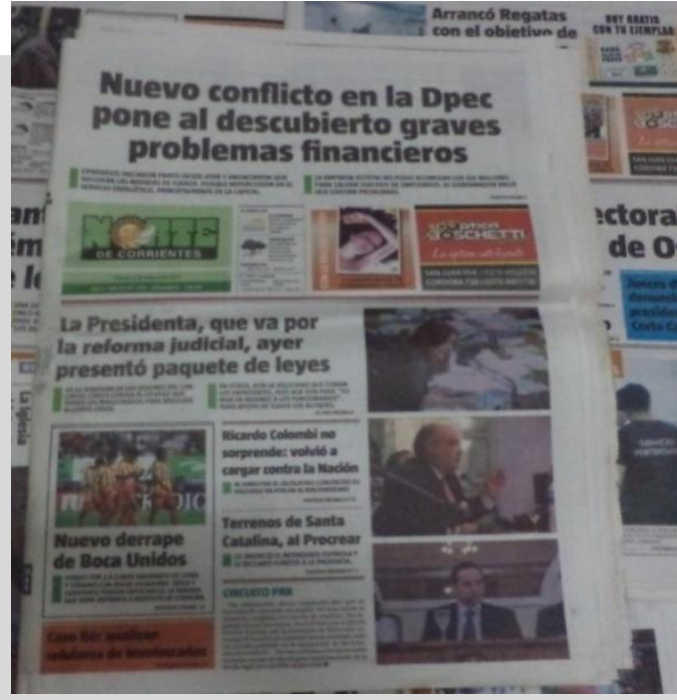

Tapa del diario Norte de Corrientes, 2 de marzo de 2013.

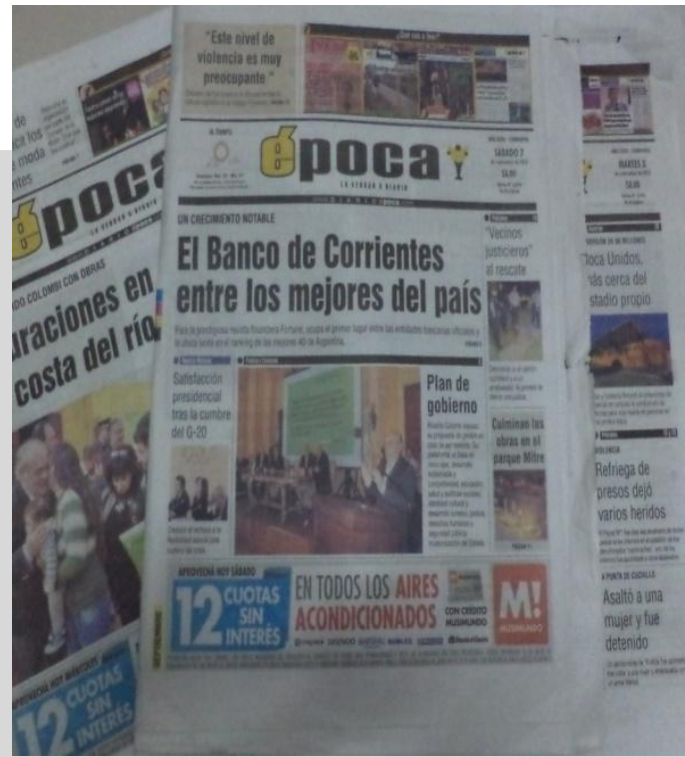

Tapa del diario Época, 7 de septiembre de 2013. 
En los tres diarios durante los cortes de marzo y junio se observaron encuadres semánticos diferentes a los encuadres de las gacetillas de prensa, pese a que los contenidos se relacionaban con las noticias de tapa. Las coincidencias, no obstante, aumentaron en septiembre, próximo a las elecciones. Por ejemplo, en la edición del 7 de septiembre, Época publicó en tapa "El Banco de Corrientes entre los mejores del país". El 6 de septiembre, la Dirección de Información Pública remitió una gacetilla con el siguiente título: "El Banco de Corrientes primero entre los oficiales y sexto en el ranking nacional de 82 entidades financieras".

Por otra parte, en el corpus seleccionado se detectaron operaciones referenciales y de designación. Tanto la DIP como los medios coincidieron en que la figura de mayor visibilidad fue la del gobernador Ricardo Colombi, visibilidad que fue acrecentándose en la medida en que se acercaba la fecha electoral. Sin embargo, en la mayoría de los casos no hubo coincidencias en la jerarquización de designaciones. Por ejemplo, en las gacetillas del 1 de marzo, en los envíos referidos a la Asamblea Legislativa, los comunicados hicieron foco en los conceptos como "progreso", "confianza social", con el pago de salarios en tiempo y forma, y con el "equilibrio fiscal". "Recuperamos la solvencia del Estado. Corrientes hoy cumple con sus compromisos, no solo paga sus deudas, ha hecho del pago de los salarios en tiempo y forma una marca registrada" (DIP, 1 de marzo de 2013). En los diarios, estas denominaciones no se jerarquizan en espacios de mayor visibilidad. Salvo excepciones como el caso mencionado de la edición del 7 de marzo del diario Época.

En el discurso del gobernador proporcionado por las gacetillas, el gobierno busca lograr un ethos de credibilidad y de adhesión. Construye una imagen de "correntinidad" que está asociado a un modelo de vida, de conservación de las tradiciones. En su enunciado construye un destinatario, el correntino, y un contradestinatario, el gobierno nacional.

Esta propuesta, es el pedestal de inicio de una Provincia que se piensa a sí misma como un modelo propio, que pueda resultar inspirador para todos los argentinos: una Provincia con políticas serias, sustentables, adecuadas a sus posibilidades, que se construye con el esfuerzo de un millón de correntinos, donde todos somos importantes y donde cada uno tiene algo para aportar (DIP, 1 de marzo de 2013).

(...) Denunció al mismo tiempo la mezquindad de las concepciones imperantes en la política nacional y el sentido profundamente discriminante de su relación con las Provincias (DIP, 1 de marzo de 2013). 
Por su parte, El Litoral no tomó las nociones de "confianza social" ni de "correntinidad" para encuadrar el acontecimiento. Abordó la construcción de un adversario político que fue jerarquizado en los titulares. En esto contribuyó el contexto electoral y de polarización de la intención de votos entre ECO y el FPV. "En pleno año electoral su alocución fue de campaña: no reparó en críticas al Gobierno nacional y-sin nombrarlo- apuntó a su principal contrincante en las urnas: Carlos 'Camau' Espínola" (EI Litoral, 2 de marzo de 2013).

En Época, el principal actor de la acción es el gobernador de la provincia de Corrientes, Ricardo Colombi. Se mencionó la gestión por lo que refiere no solo a la campaña electoral, sino también a la institucionalidad del acontecimiento. Al igual que lo observado en las gacetillas, el enunciador medio de comunicación construyó un otro, un contradestinatario, que se denomina en la noticia como"la política nacional con matriz en los 90'". Esta construcción se observó en la narrativización del discurso original.

En este punto también se diferenció del Gobierno nacional al asegurar que desde la Capital Federal sólo se apoya a los que aceptan ser parte de la misma política y que en Corrientes se otorgan beneficios a los municipios sin pensar en su alineamiento político (Época, 2 de marzo de 2013).

En la noticia, además, se hizo mencióna un término clave en el discurso del gobernador, la noción de "progreso". En cuanto a la construcción de la noción de correntinidad, en la noticia estuvo implícita al marcar la diferenciación entre gobierno nacional y gobierno provincial:
En ese plano afirmó que "la construcción de una Corrientes grande debe partir del afianzamiento de nuestras instituciones, de nuestros valores y de nuestras virtudes y no como el furgón de cola de los caprichos que otros y en otros lugares pergeñan". (Ibídem).

En Norte de Corrientes, el principal actor de la acción puesto en el relato fue el gobernador. A diferencia de la gacetilla que construye el acontecimiento en torno al acto institucional de apertura de sesiones ordinarias y que jerarquiza denominaciones enunciadas por el mandatario provincial como "confianza social" y "progreso", el medio gráfico hizo foco en la campaña electoral y no connotó un tipo de comunicación proactiva, de exposición de políticas de Estado nide búsqueda del consenso. Por el contrario, en el título denominó la acción del mandatario como "victimización" ante sus adversarios políticos. En el cuerpo de la noticia se profundizó dicha denominación: 
"Reclamó fondos adeudados y pidió nueva ley de coparticipación. Castigó a la oposición porque no le aprobó nuevos endeudamientos" (Norte de Corrientes, 2 de marzo de 2013).

Los reenvíos en las noticias hacia los comunicados dan cuenta de operaciones intertextuales. Para su identificación se trabajó con dos herramientas teóricometodológicas: las fuentes de información y el dicho referido. Este último puede clasificarse como selección, estilo directo, indirecto y actancialización.

En las noticias seleccionadas predomina el Estado como fuente de información. Las gacetillas de la DIP integran el grupo de fuentes oficiales y se observan extractos en el corpus seleccionado; sin embargo, no son mencionadas como tales. Por ejemplo, en el tratamiento de la apertura de la Asamblea Legislativa, en El Litoral se elucidaron extractos de los comunicados sin mentarlos. De igual modo se observó en Época y en Norte de Corrientes.

"Estamos -remarcó- entre las dos provincias con mejor performance fiscal del país y sin embargo no hemos logrado que nuestra legislatura nos acompañe en un proceso orientado a incrementar la inversión y mejorar la infraestructura" (...). (DIP, 1 de marzo de 2013).

Aseguró que Corrientes está "entre las dos provincias con mejor performance fiscal del país", y sin embargo su gestión "no tuvo el acompañamiento de esta Legislatura en el proceso financiero orientado a incrementar la inversión y mejorar la infraestructura", en referencia a los $\$ 1.300$ millones en créditos que no se aprobaron el año pasado. (Norte de Corrientes, 2 de marzo de 2013, p. 3)

En cuanto al tipo de fuente, esta generalmente posee notoriedad, al ser una figura pública con representatividad de un sector y es gubernamental. Sin embargo, no se pudo establecer que en todas las noticias que integran el corpus la única fuente sean las gacetillas de la DIP. En algunos casos se construye el acontecimiento incorporando otras voces, también con representatividad de un sector, como los sindicatos. Por ejemplo, en la edición del 7 de marzo de 2013 de El Litoral sobre el tratamiento de un acuerdo salarial entre el Gobierno y los sindicatos docentes, el diario construye el acontecimiento con fuentes sindicales e información enviada por la oficina de prensa gubernamental.

"Vamos a salir por las escuelas y conversar con los compañeros sobre la oferta de la Provincia. Queremos que sea una propuesta 
integral que considere otras cuestiones laborales, como la estabilidad en todos los niveles, nomenclador, infraestructura edilicia y paritarias", resaltó el secretario general de Suteco, Fernando Ramírez.

(...) El Gobierno provincial habla de un preacuerdo para la recomposición de 600 pesos en el salario educativo que se hará efectivo en varios tramos.(El Litoral, 7 de marzo de 2013).

Respecto al modo de referir las gacetillas se detectaron selecciones de las mismas, principalmente para tomar declaraciones que pueden ser de estilo directo, indirecto o narrativizado.

"Están equivocados", le dijo Colombi a los gobernadores kirchneristas que el viernes pasado vinieron a apoyar la candidatura a gobernador del intendente Camau Espínola. Y se jactó luego al señalar que "somos la única provincia que no tuvo que emitir títulos, bonos, deuda, ni nada que se asemeje para hacer frente a las obligaciones fundamentales de Estado, porque nos manejamos como corresponde, con lo que ingresa diariamente, no generamos deuda, no complicamos el futuro de los correntinos". "Nos quieren hablar de economía y tienen el Banco (del Chaco) fundido", agregó luego para seguir desacreditando las críticas kirchneristas. (DIP, 2 de septiembre de 2013).

Se mofó de los funcionarios nacionales que "vienen a hablar de economía y tienen el Banco fundido" y, en particular, manifestó que "otro de acá al sur", por el entrerriano Uribarri (sic), "ni banco tiene y nos vienen a hablar de economía". (Época, 3 de septiembre de 2013).

\section{Algunas conclusiones preliminares}

Si el poder del discurso se observa en otro que es su efecto, las gacetillas de la DIP generan un efecto de reconocimiento en la prensa que no puede considerarse lineal, sino dentro de un campo de efectos posibles, es decir, a la luz de las condiciones de producción/lectura de los medios analizados. Por ello, dentro de las restricciones de reconocimiento que operan en conjunto con el discurso gubernamental en el discurso de la prensa se pueden mencionar algunos elementos como la población y distribución geográfica de la provincia, su estructura económica, el origen político de los medios y una política provincial de alianzas partidarias en constante modificación, las elecciones 
de 2013, las especificidades del discurso de la información; la publicidad privada y la pauta estatal, la imagen del lector que mantienen los periodistas, las rutinas periodísticas y políticas profesionales, y/o la línea editorial.

Inclusive, en los tres cortes, los diarios mantienen prácticamente la misma tendencia de uso de los comunicados como recuadros y como cabezas de página, es decir, no predominaron como notas secundarias ni noticias breves. Tal como observamos en el apartado anterior, luego de un relevamiento cuantitativo se constató una mayor presencia de temas y/o contenidos coincidentes con gacetillas en el cuerpo de los medios analizados, pero la cantidad fue escasa en los espacios de mayor visibilidad, esto es, en las tapas de los medios gráficos mencionados.

Si bien hubo un incremento de los despachos de partes oficiales de marzo a junio y de junio a septiembre, ello no se replicó en la portada de los diarios de la misma manera. En El Litoral, de línea oficialista, marzo fue el mes con mayor porcentaje de coincidencias en portada con gacetillas de la DIP. En Época, también de línea oficialista, se observó un leve aumento de coincidencias de junio a septiembre. En Norte de Corrientes, de línea opositora, la tendencia fue en descenso en la portada, pero de aumento en el cuerpo del diario.

Esta tendencia incluye a los comunicados de todas las áreas temáticas remitidas por la oficina de prensa como ser salud, educación, desarrollo humano y cultura, entre otras. No obstante, los envíos relacionados con el Ejecutivo provincial y la inauguración de obras públicas obtuvieron los espacios de máxima jerarquización en los diarios analizados en septiembre, construyendo el acontecimiento como parte de la campaña electoral.

Qué publican y qué no publican en primera plana los diarios está relacionado con un primer efecto de reconocimiento del discurso gubernamental en la prensa que consiste en la construcción de una temporalidad social propia, en la cual la agenda electoral se conjuga con la gestión pública, en lavisibilización del llamado fenómeno de campaña permanente. Los temas políticos, además, comparten espacio en primera plana con otros tópicos de producción propia del medio de comunicación que conforman el universo temático de los diarios analizados como policiales y deportes.

De acuerdo con un primer relevamiento durante el periodo seleccionado, los temas de tapa, en la mayoría de los casos, no mantienen coincidencias con los envíos que realiza el Gobierno de la Provincia de Corrientes, sino que predominan los temas policiales y deportivos. Los temaspolíticosse encuentran en tercera instancia en cuanto a cantidad de publicaciones en portada. Sin embargo, a medida que se aproxima la fecha de los comicios de septiembre, el tópico campaña electoral -que se observa desde marzo-tiene mayor espacio de jerarquización en los tres diarios analizados, tal como lo expusimos anteriormente.

En este periodo, los medios gráficos otorgan mayor visibilidad a las gacetillas que exhiben al gobernador como el principal actor de la acción, sea de línea editorial 
oficialista u opositora. Los comunicados construyen los acontecimientos que divulgan como actos institucionales de la gestión del gobierno, sin mencionar la actividad proselitista. En los diarios estas actividades, que generalmente se relacionan con la inauguración de obras públicas, se construyen en tapa como parte de la campaña electoral. En el cuerpo se publican en las secciones actualidad-política e interiorprovincia.

Como hemos mencionado, una regla de reconocimiento es que la lectura por parte de la prensa de las gacetillas no necesariamente debe ser lineal -es decir, transcripciones de los comunicados-ya que en los titulares se construyen acontecimientos con un sentido diferente a los titulares de los comunicados. Esto se observa especialmente en las noticias de mayor visibilidad, es decir, en las que fueron jerarquizadas como título principal y foto principal de tapa. Esto, por lo tanto, permite establecer la presencia de un encuadre semántico diferente. Aunque vale señalar que en el relevamiento se han registrado excepciones a esta norma de lectura.

Estas diferencias de construcción del acontecimientoentre los comunicados y la prensa en los titulares connotan que el discurso político-gubernamental no genera un efecto inmediato de adhesión en la prensa o, en términos veronianos, un efecto ideológico sobre los medios de comunicación. La construcción de la noticia implica negociaciones y tensiones donde intervienen varios condicionamientos, más allá de la línea editorial.

Sin embargo, a escala de las referencias de personajes y denominaciones, el discurso de la información coincide con el discurso gubernamental en posicionar al Estado como instancia generadora de noticias y como una de las principales fuentes de información, siendo el gobernador Ricardo Colombi el actor de mayor visibilidad en los tres diarios analizados, sean estos medios de línea oficialista u opositora.

Vale aclarar que nose observa plena coincidencia entre las denominaciones expuestas por la DIP y las jerarquizadas en titulares por la prensa. Por ejemplo, en su discurso, el gobierno se representa como un regulador social que mantiene el orden social en la provincia. Los medios de comunicación, por su parte, hacen foco en el conflicto, aunque dentro del marco institucional permitido como ser las negociaciones con sindicatos y la contienda electoral. Los diarios, además, suman otros actores que tensionan con el discurso gubernamental como el caso de sindicalistas y adversarios políticos.

Estas tensiones en el interior del relato noticioso contribuyen a la construcción propia de la temporalidad social por parte de los medios. La presencia de otros actores y fuentes en la noticia, a su vez, propende a reforzar un efecto de objetividad y de credibilidad por parte de los diarios hacia sus respectivas instancias de recepción, hacia sus lectores, lo cual se relaciona con las especificidades del discurso de la información.

Como hemos mencionado, el Estado es una de las principales fuentes de información, lo cual se puede observar en la selección de extractos de las gacetillas en el cuerpo de 
las noticias analizadas. En casi todos los casos relevados no se menciona el origen de los comunicados como fuente de información en el relato noticioso. Esto nos lleva a establecer que los partes oficiales generan en los medios un efecto de credibilidad. La información remitida por la DIP es verosímil para los diarios. En esta instancia puede observarse, por lo tanto, un efecto de verdad.

Así como los medios de comunicación generan efecto de verdad entre sus lectores con estrategias discursivas tales como mencionar fuentes de información, citas textuales y un contrato de lectura a través del cual la instancia de recepción no requiere comprobar la verosimilitud del hecho que el medio relata, los diarios mantienen un contrato similar con la oficina gubernamental de prensa debido a que los medios no mencionan en sus textos a los comunicados como fuente de información. Se genera, así, un efecto de apropiación del discurso gubernamental con restricciones anteriormente mencionadas.

Aquí es necesario establecer una diferencia entre el efecto de credibilidad y de adhesión. El medio de comunicación al utilizar datos, información y citas proporcionadas por la DIP considera verosímil el acontecimiento en construcción debido al contrato que media entre ambas instancias. Pero ello no significa que la selección de extractos represente una adhesión o un efecto ideológico del discurso gubernamental en la prensa, como podría suceder en la relación entre el discurso político y los militantes, o entre el discurso religioso y los creyentes.

Uno de los indicadores de la ausencia de un efecto de adhesión plena podemos encontrar en el plano del dicho referido. Se han observado en las noticias seleccionadas recursos que generan un efecto de toma de distancia entre el dicho original y el dicho referido por los diarios. Estos recursos consisten en citas textuales de estilo directo e indirecto.

El poder del discurso gubernamental no es lineal, no se observa en los titulares de la prensa una reproducción directa en titulares de los comunicados oficiales. Si bien prevalecen en los diarios las gacetillas como una de las principales fuentes de información y el gobernador es el actor de mayor visibilidad en tiempos electorales, el poder del discurso gubernamental está atravesado por una serie de condiciones sociales de reconocimiento que operan en una compleja red de significación.

\section{Bibliografía}

ApezteguíaAvellán, F. (2005). Las estrategias comunicativas del Gobierno de la Provincia de Corrientes. Tesis de Grado. Universidad Nacional del Nordeste. Corrientes, Argentina.

Artese, M. (2005). Lucha de clases y enfrentamiento simbólico: Corrientes 1999.
Razón
$y$
Revolución,
$4 . \quad$ Recuperado
de

http://www.razonyrevolucion.org/textos/revryr/RyR14/ryr14-artese.pdf 
Arrueta, C. (2010). ¿Qué realidad construyen los diarios? Una mirada desde el periodismo en contextos de periferia. Buenos Aires: La Crujía.

Barrios, G. (2005). De la plaza al puente: Correntinos en lucha. En Roze, P. y Pratesi, A. (comp.) Conflictos centrales en la periferia de la globalización, Libros en Red, pp. 97119.

Recuperado

de http://www.insumisos.com/lecturasinsumisas/Conflictos\%20en\%20la\%20periferia\% 20de\%20la\%20globalaizacion.pdf

Behrend, J. (noviembre, 2003). Nota para el desentramado de la relación entre clientelismo y la protesta social. En A. Fernández (Presidencia), La política en un mundo incierto. Simposio llevado a cabo en el VI Congreso Nacional de Ciencia Política, Sociedad Argentina de Análisis Político. Rosario, Argentina. Recuperado de http://www.saap.org.ar/esp/docs-congresos/congresossaap/VI/areas/06/behrend.pdf

Bitonte, M. E. (2009). Tres aportes de la noción de operaciones: Verón, Fisher y Goodman. Figuraciones, 6 Recuperado de http://www.revistafiguraciones.com.ar/numeroactual/recorrido.php?idn=6\&idr $=45$

Boletín Oficial de la República Argentina (14 de diciembre, 2009). Ley N² 26.571 de Democratización de la representación política, la transparencia y la equidad electoral. . Recuperado del sitio de internet del Boletín Oficial de la República Argentina http://www.boletinoficial.gov.ar/DisplayPdf.aspx?s $=01 \& f=20091214$

Charaudeau, P. (2003). Eldiscurso de la información. La construcción del espejo social. Barcelona: Gedisa.

_ (2009). Reflexiones para el análisis del discurso populista. Discurso y Sociedad, 3. Recuperado de http://www.dissoc.org/ediciones/v03n02/DS3(2)Charaudeau.html

Código Electoral de Corrientes (12 de julio, 2001). Decreto Ley $N^{\circ} 135$. Recuperado de http://www.juscorrientes.gov.ar/normativas/leyes-electorales/docs/codelectoral.pdf.

De los Reyes, A. (2012). El sistema de medios en Corrientes, un vínculo entre lo público y lo privado. Una década desde la perspectiva de la Economía Política de la Comunicación. Tesis de grado. Universidad Nacional del Nordeste. Corrientes, Argentina.

DEyC (s.f. a). Perfil económico. Recuperado del sitio de Internet de la Dirección de Estadística y Censos http://www.deyc-corrientes.gov.ar/perfil-economico.html

_ (2013 b). PBG Anual. Recuperado de http://www.deyc-corrientes.gov.ar/tema/102pbg-anual.html

Elizalde, L.; Fernández Pedemonte, D. y Riorda, M. (2006).La construcción del consenso. Gestión de la comunicación gubernamental. Buenos Aires: La Crujía.

_ (2011). La gestión del disenso. Buenos Aires: La Crujía.

Escudero Chauvel, L. (1996). Malvinas: el gran relato. Fuentes y rumores en la información de guerra. Barcelona: Gedisa. 
Escudero Chauvel, L. (2002). (comp.) La comunicación política. Transformaciones del espacio público. Designis, 2. Barcelona: Gedisa.

Escudero Chauvel, L. y García Rubio, S. (2007). (ed.)Democracias de opinión. Medios y comunicación política. Buenos Aires: La Crujía.

Fernández Constantinides, M. (2011). El discurso político y la politicidad de los discursos. Question. Universidad Nacional de La Plata. La Plata.

Guber, R. (10 de abril, 2002). La dimensión cultural de la crisis de Corrientes. Rebelión. Recuperado de http://www.rebelion.org/hemeroteca/sociales/guber100402.htm

Instituto Nacional de Estadística y Censos (2013a). Encuesta permanente de hogares. Incidencia de la pobreza y de la indigencia. Resultados del primer semestre de 2013. Recuperado

http://www.indec.gov.ar/uploads/informesdeprensa/pob_tot_1sem13.pdf

_ (2013b). Proyecciones provinciales de población por sexo y grupo de edad 2010-2040. Serie 56, Tomo I. Buenos Aires: Indec. Recuperado de http://www.indec.mecon.ar/nuevaweb/cuadros/2/proyecciones_prov_2010_2040.pd $\mathrm{f}$

_ (2013c). Encuesta Permanente de Hogares. Indicadores Socioeconómicos. Resultados del Tercer Trimestre de 2013. Buenos Aires: Indec. Recuperado de http://www.indec.gov.ar/novedades.asp

Izurieta, R.; Perina, R. y Arterton, C. (2002). (ed.) Estrategias de comunicación para gobiernos. Buenos Aires: La Crujía.

McCombs, M. (2006). Estableciendo la agenda. Buenos Aires: Paidós.

Rincón, O. (2004). Comunicación Política en América Latina. Bogotá: Centro de Competencia en Comunicación para América Latina. Recuperado de http://www.c3fes.net.

Sartori, G. (1998). Homo Videns. La sociedad teledirigida. Buenos Aires: Taurus.

Solís Carnicer, M. (2006). Cultura política en Corrientes. Partidos, elecciones y prácticas electorales (1909- 1930). Tesis doctoral. Universidad Nacional de Cuyo. Mendoza, Argentina. Recuperado de http://bdigital.uncu.edu.ar/objetos_digitales/2756/solscarnicerculturapolticacorrien tes.pdf

Verón, E. (1971). Ideología y comunicación de masas: la semantización de la violencia política. Lenguaje y comunicación social. Buenos Aires: Nueva Visión.

_ (1980). Discurso, poder, poder del discurso. Análisis de primer coloquio de semiótica. Río de Janeiro: PUC/Ediciones.

_ (1987a). Construir el acontecimiento. Buenos Aires: Gedisa.

_ (1987b). La palabra adversativa. Observaciones sobre la enunciación política. En Verón, et. al., El discurso político. Lenguajes y acontecimientos. Buenos Aires: Hachette, pp. 11-26. 
_ (1992). Interfaces. Sobre la democracia audiovisual avanzada. En Ferry, J. M. y Wolton, D. (ed.) El nuevo espacio público. Barcelona: Gedisa, pp. 124-139.

_ (1993). La semiosis social. Fragmentos de una teoría de la discursividad. Barcelona: Gedisa.

_ (2004). Fragmentos de un tejido ( $2^{\mathrm{a}}$ ed.) Barcelona: Gedisa.

Verón, E. y Sigal, S. (1988). Perón o muerte. Los fundamentos discursivos del fenómeno peronista. Buenos Aires: Hyspamérica.

Villarino, J. y Sternbeng, C. (2005). La inestabilidad del sistema político correntino y el surgimiento de actores de base territorial (1993- 2003). Revista SAAP,Vol. 2, No 2 , septiembre 2005, pp. 293-317. Recuperado de http://www.saap.org.ar/esp/docsrevista/revista/pdf/2-2/villarino.pdf 